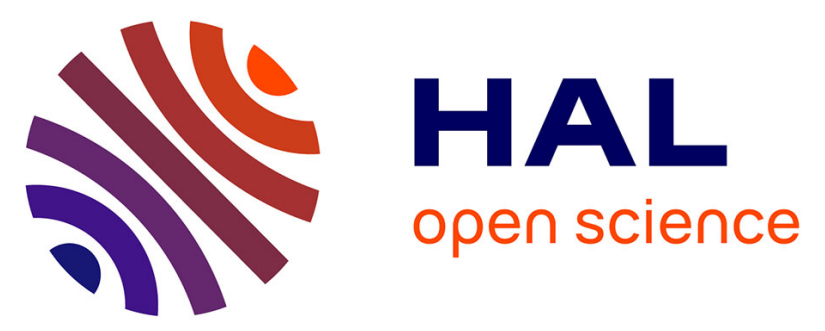

\title{
Severe Obesity Impacts Recurrence-Free Survival of Women with High-Risk Endometrial Cancer: Results of a French Multicenter Study
}

Geoffroy Canlorbe, Sofiane Bendifallah, Emilie Raimond, Olivier Graesslin, Delphine Hudry, Charles Coutant, Cyril Touboul, Géraldine Bleu, Pierre Collinet, Emile Darai, et al.

\section{To cite this version:}

Geoffroy Canlorbe, Sofiane Bendifallah, Emilie Raimond, Olivier Graesslin, Delphine Hudry, et al.. Severe Obesity Impacts Recurrence-Free Survival of Women with High-Risk Endometrial Cancer: Results of a French Multicenter Study. Annals of Surgical Oncology, 2015, 22 (8), pp.2714-2721. 10.1245/s10434-014-4295-0 . hal-01103385

\section{HAL Id: hal-01103385 \\ https://hal.sorbonne-universite.fr/hal-01103385}

Submitted on 14 Jan 2015

HAL is a multi-disciplinary open access archive for the deposit and dissemination of scientific research documents, whether they are published or not. The documents may come from teaching and research institutions in France or abroad, or from public or private research centers.
L'archive ouverte pluridisciplinaire HAL, est destinée au dépôt et à la diffusion de documents scientifiques de niveau recherche, publiés ou non, émanant des établissements d'enseignement et de recherche français ou étrangers, des laboratoires publics ou privés. 
1 Full names, degrees and affiliations for all authors

2 Geoffroy Canlorbe, $\mathrm{MD}^{1}$, Sofiane Bendifallah, $\mathrm{MD}^{1,2}$, Emilie Raimond, $\mathrm{MD}^{3}$, Olivier

3 Graesslin, $\mathrm{MD}, \mathrm{PhD}^{3}$, Delphine Hudry, $\mathrm{MD}^{4}$, Charles Coutant, $\mathrm{MD}, \mathrm{PhD}^{4}$, Cyril Touboul

$4 \mathrm{MD}, \mathrm{PhD}^{5}$, Géraldine Bleu, $\mathrm{MD}^{6}$, Pierre Collinet, $\mathrm{MD}, \mathrm{PhD}^{6}$, Emile Darai, $\mathrm{MD}, \mathrm{PhD}^{1,7}$,

$5 \quad$ Marcos Ballester, $\mathrm{MD}, \mathrm{PhD}^{1,7}$

$6 \quad{ }^{1}$ Department of Obstetrics and Gynaecology, Tenon University Hospital, Assistance Publique

7 des Hôpitaux de Paris (AP-HP), University Pierre and Marie Curie, Paris 6, Institut

8 Universitaire de Cancérologie (IUC), Paris, France;

92 INSERM UMR S 707, Epidemiology, Information Systems, Modeling, University Pierre 10 and Marie Curie, Paris, France;

$11{ }^{3}$ Department of Obstetrics and Gynaecology, Institute Alix de Champagne University 12 Hospital, Reims, France;

$13{ }^{4}$ Centre de lutte contre le cancer Georges François Leclerc, Dijon, France;

$14{ }^{5}$ Department of Obstetrics and Gynecology, Centre Hospitalier Intercommunal, Créteil, 15 France;

$16{ }^{6}$ Department of Obstetrics and Gynecology, Centre Hospitalier Régional Universitaire, Lille, 17 France;

$18 \quad{ }^{7}$ INSERM UMR S 938, University Pierre et Marie Curie, Paris, France

20 Full mailing and e-mail address; telephone; and fax number of the author to whom

21 correspondence and proofs should be sent

22 Doctor Geoffroy CANLORBE, MD

23 Service de Gynécologie-Obstétrique

24 Hôpital Tenon, 4 rue de la Chine, 75020 Paris, France

25 Phone: 33156016019 ; Fax: 33156017317 ; e-mail : geoffroy.canlorbe@tnn.aphp.fr 
Title and subtitle of the paper

Severe obesity impacts recurrence-free survival of women with high-risk endometrial cancer: results of a French multicentre study

\section{A shortened version of the title for the running head}

32

Severe obesity and survival in endometrial cancer

33

34 Disclosure of any commercial interest

35 None of the authors had any financial and personal relationships with other people or organizations that could inappropriately influence this work.

37 There was no external funding for this project. Time and effort were volunteered by the 38 authors.

Synopsis

44 This multicentre study included 729 women with endometrial cancer. Body mass index had 45 no impact on recurrence free survival (RFS) in obese women in low/intermediate-risk groups. A BMI $\geq 35$ was correlated to a poorer RFS for women in the high-risk group. 
Background. Studies focusing on the impact of obesity on survival in endometrial cancer (EC) have reported controversial results and few data exist on the impact of obesity on recurrence rate and Recurrence Free Survival (RFS). The aim of this study was to assess the impact of obesity on surgical staging and RFS in EC according to the European Society of Medical Oncology (ESMO) risk groups.

Methods. Data of 729 EC women who received primary surgical treatment between January 2000 and December 2012 were abstracted from multicentre database (training set). RFS distributions according to body-mass index (BMI) in each ESMO risk group were estimated using the Kaplan-Meier method. Survival was evaluated using the log-rank test. The Cox proportional hazards model was used to determine influence of multiple variables.

Results. Distribution of the 729 women with EC according to BMI was: BMI $<30$ (n=442; $60.6 \%), 30 \leq \mathrm{BMI}<35(\mathrm{n}=146 ; 20 \%)$ and $\mathrm{BMI} \geq 35(\mathrm{n}=141 ; 19.4 \%)$. Nodal staging was less likely to be performed in women with $\mathrm{BMI} \geq 35(72 \%)$ than for those with $\mathrm{BMI}<30(90 \%)$ $(\mathrm{p}<0.0001)$. With a median follow-up of 27 months (IQR: 13-52), the 3-year RFS was 84.5\%. BMI had no impact on RFS in obese women in low/intermediate-risk groups but a BMI $\geq 35$ was independently correlated to a poorer RFS (HR=12.5 (95\% CI, 3.1-51.3)) for women in the high-risk group.

Conclusion. Severe obesity negatively impacts RFS in women with high-risk EC underlining the importance of complete surgical staging and adapted adjuvant therapies in this subgroup of women. 


\section{Introduction}

78 Obesity is a well-known risk factor for endometrial cancer (EC) $(1,2)$ : women with a bodymass index (BMI) over 30 have a relative risk of death from EC of 2.53 compared to women of normal weight (3). This increased risk particularly concerns type I ECs, which are

\section{列} associated with long-duration unopposed estrogenic stimulation and arise in a setting of endometrial hyperplasia (4).

In Europe, surgical treatment of presumed early-stage EC is based on the European Society of Medical Oncology (ESMO) guidelines, according to the presumed risk of recurrence. For women with low- or intermediate-risk EC, a total hysterectomy with bilateral salpingooophorectomy is recommended. Pelvic and para-aortic lymphadenectomy is recommended for women of high-risk EC (5). Because of associated comorbidities or technical difficulties related to obesity, surgeons are sometimes reluctant to perform complete surgical staging including lymphadenectomy. Moreover, difficulties are also encountered to adapt adjuvant treatment, either for radiotherapy (6) or chemotherapy (7), with a potential impact on survival. However, studies focusing on the impact of obesity on survival in EC have reported controversial results (2, 7-20) and few data exist on the impact of obesity on recurrence rate and Recurrence-Free Survival (RFS) according to the ESMO risk groups.

Hence, the purpose of this multicentre study was to assess the impact of obesity on surgical staging and RFS in EC according to the ESMO risk groups. 


\section{Material And Methods}

103

104

\section{Study population}

105 Data of all women who received primary surgical treatment between January 2000 and 106 December 2012 were abstracted from five institutions with maintained EC databases in 107 France (Tenon University Hospital, Reims University Hospital, Dijon Cancer Center, Lille 108 University Hospital, Creteil University Hospital), and from the Senti-Endo trial (21). All the women had given informed written consent to participate in the study. The research protocol was approved by the institutional review board of the French College of Obstetrics and

111 Gynecology (CEROG 2014-GYN-020).

112 Clinical and pathologic variables included patient's age, BMI, surgical procedure, 2009 FIGO 113 stage, final pathological analysis (histological type and grade, depth of myometrial invasion, 114 lymphovascular space invasion (LVSI) status) and adjuvant therapies. BMI was defined as weight (kg) divided by squared height (m2), both measured at the time of diagnosis, and expressed in $\mathrm{kg} / \mathrm{m} 2$. Normal bodyweight was defined as a BMI of $<25 \mathrm{~kg} / \mathrm{m} 2$, obesity a BMI

$117 \geq 30 \mathrm{~kg} / \mathrm{m} 2$ and severe obesity a BMI of $\geq 35 \mathrm{~kg} / \mathrm{m} 2)(22)$.

118 Histological staging and grading was performed according to the 2009 FIGO classification 119 (23) system on the basis of the final evaluation of the pathological specimen. The risk of 120 recurrence was defined according to the ESMO guidelines. Histological type I corresponds to 121 endometrioid cancer whatever the histological grade. Histological type 2 corresponds to clear 122 cell carcinomas, serous carcinomas and carcinosarcomas. The three risk groups of EC are 123 defined as follows: low-risk (type 1 EC FIGO stage IA grade 1 or 2); intermediate-risk (type 1 124 EC, FIGO stage IA grade 3, or FIGO stage IB grade 1 or 2); high-risk (type 1 EC, FIGO stage 125 IB grade 3, and type 2 EC) (5). 
128 All women underwent primary surgical treatment including at least total hysterectomy with 129 bilateral salpingo-oophorectomy. Until 2010, systematic pelvic lymphadenectomy was 130 recommended and para-aortic lymphadenectomy was only performed in case of high-risk EC 131 or metastatic pelvic lymph node. Since the publication of French guidelines in 2010 (24), 132 lymphadenectomy was no longer recommended for women with low/intermediate risk EC.

133 Women with early-stage EC who were enrolled in the Senti-Endo trial (21), from July 2007 to 134 August 2009, underwent a pelvic sentinel lymph node biopsy (SLN) (25) with systematic 135 pelvic lymphadenectomy. When the pelvic SLN was found to be metastatic at intraoperative 136 histology or after final histology, a para-aortic lymphadenectomy was recommended. 137 Adjuvant therapy was administered according to multidisciplinary committees based on 138 French guidelines (24).

139 According to French guidelines (24), frequency of clinical follow-up was every 3-4 months 140 for the first 2 years, and then with a 6 months interval until 5 years and every year thereafter. 141 Further imaging investigations were carried out if clinically indicated.

142 Disease recurrence was diagnosed either by biopsy or imaging studies and defined as a 143 relapse without differentiating between their local or distant nature. RFS was calculated in 144 months from the date of surgery to recurrence. Any woman not presenting for scheduled 145 follow-up visits was contacted.

147 Statistical analysis

148 Statistical analysis was based on Student's t-test or ANOVA test, as appropriate, for continuous variables, and the Chi-square test or Fisher's exact test, as appropriate, for 150 categorical variables. Values of $\mathrm{p}<0.05$ were considered to denote significant differences. 
151 The Kaplan-Meier method was used to estimate the survival distribution and comparisons of

152 survival were made by the use of the log-rank test. The Cox proportional hazards model was 153 used to account for the influence of multiple variables.

154 Data were managed with an Excel database (Microsoft, Redmond, WA) and analyzed using R $155 \quad$ 3.0.1 software, available online.

\section{Results}

\section{Characteristics of the whole population (Table 1)}

162 A total of 729 women were included in the study. The median BMI was $28 \mathrm{~kg} / \mathrm{m} 2$ (inter163 quartile range, IQR: 24-33) and the distribution as follows: $B M I<30$ ( $n=442 ; 60.6 \%$ ), $30 \leq \mathrm{BMI}<35(\mathrm{n}=146 ; 20 \%)$ and $\mathrm{BMI} \geq 35(\mathrm{n}=141 ; 19.4 \%)$.

165 Women with severe obesity were more likely to be younger (63 years old for women with $166 \mathrm{BMI} \geq 35$ vs. 65.5 years old for those with a $\mathrm{BMI}<30, \mathrm{p}=0.000873$ ). More women with severe 167 obesity had grade 1 and type 1 EC compared to non-obese women (61\% vs. $45 \%$ and 96\% vs. 168 84\%, respectively). A greater proportion of women with severe obesity met the criteria for the 169 low-risk of recurrence group ( $56 \%$ with a $\mathrm{BMI} \geq 35$ vs. $40 \%$ for a $\mathrm{BMI}<30$ ), while thinner 170 women had high-risk EC ( $23 \%$ for a $\mathrm{BMI}<30$ vs. $12 \%$ for a $\mathrm{BMI} \geq 35)$. However, depth of 171 myometrial invasion, LVSI status and nodal involvement did not differ according to BMI. All 172 women underwent at least a hysterectomy with bilateral salpingo-oophorectomy. Women 173 with a higher BMI were less likely to undergo nodal staging: $72 \%$ of women with a BMI $\geq 35$ 174 compared to $90 \%$ in women with a $\mathrm{BMI}<30(\mathrm{p}<0.0001)$. Among the 39 women with $\mathrm{BMI} \geq 35$ 175 who didn’t underwent lymphadenectomy, nodal staging was recommended in three cases 
176 (7.7\%) and not performed due to severe comorbidity. Among the women who underwent 177 nodal staging, no difference in the number of lymph nodes removed was found according to 178 BMI.

Characteristics of obese women according to ESMO risk of recurrence groups (Table 2)

181 The number of obese women with low-, intermediate- or high-risk EC was 137/287 (48\%), 99/287 (34\%) and 51/287 (18\%), respectively. In the low- and intermediate-risk groups, a 183 lower proportion of women with a $\mathrm{BMI} \geq 35$ had nodal staging compared to women with a $\mathrm{BMI}<35(\mathrm{p}<0.05)$. In the high-risk group, age, comorbidities (diabetes and hypertension), histological and therapeutic characteristics did not differ according to BMI.

\section{Recurrence rate and RFS}

With a median follow-up of 27 months (IQR: 13-52), 103 women (13.9\%) experienced a recurrence and 72 (9.7\%) died. The 3-year RFS was 84.5\%. We found no difference in RFS according to BMI subgroups (Figure 1).

191 BMI had no impact on RFS in obese women in the low- and intermediate-risk groups.

192 In the high-risk group of obese women, a lower RFS was found for those with a BMI $\geq 35$ 193 compared to those with a $\mathrm{BMI}<35$ (Figure 2). Among women in the high-risk group, 194 multivariate analysis including BMI $(<$ or $\geq 35)$, age $(<$ or $\geq 65)$, histological type, LVSI 195 status, adjuvant therapies (VBRT, EBRT and chemotherapy) and nodal staging, showed that $196 \mathrm{BMI} \geq 35$ was independently correlated to a poorer RFS (HR=12.5 (95\% CI, 3.1-51.3)). 
202 Our results show that women with severe obesity are more likely to have low/intermediate203 risk ECs with similar RFS than non-obese women. In contrast, among obese women with 204 high-risk EC, those with severe obesity had a lower RFS.

205 When considering the whole population of obese women with EC, regardless the distribution 206 according to the ESMO risk groups, no relation was observed between obesity and decrease 207 in RFS. These data are in agreement with those of a review of 12 studies evaluating the 208 relation between obesity and survival of patients with EC (26) reporting no impact of obesity 209 either on progression-free $(7-9,13,17)$ or disease-specific survival $(15,16)$. Similarly, in a 210 study of 1070 women with EC treated within the MRC ASTEC randomized trial with a 211 median follow-up of 34.3 months, Crosbie et al. found no influence of obesity on RFS (27). 212 More recently, in a study including 2596 women with EC, Gunderson et al. found no 213 association between obesity and disease-specific mortality (28). However, no attempt was 214 made to evaluate the impact of obesity on RFS according to ESMO risk groups.

215 In the current study, when analyzing RFS in obese patients according to ESMO risk groups, 216 we noted that patients with severe obesity were more likely to have low grade tumors (1-2) 217 type 1 EC and limited myometrial infiltration corresponding to low/intermediate ESMO risk 218 groups. Although obese patients had a lower rate of lymphadenectomy, no difference in RFS 219 in patients with ESMO low/intermediate risk groups was observed between severely obese 220 and obese patients. These results are in full agreement with those of the meta-analysis of May 221 et al. underlining the absence of impact of lymphadenectomy on RFS (29). This absence of 222 difference in RFS can be explained by the low incidence of lymph node metastases in this 223 sub-group of patients. Moreover, patients with low/intermediate risk represented about three 224 quarters of the population in our study, as in previous reports, and this explains why no 225 difference in survival according to BMI was found taking into account the whole population. 
226 For patients with severe obesity in the ESMO high-risk group, a decrease in RFS was 227 observed. This is partly in accordance with Arem et al. who found that patients with poorly 228 differentiated tumors had an EC-specific mortality of HR 1.39 (95\% CI 1.04-1.85) per 5-unit 229 BMI increase whereas no differences were detected for well differentiated or moderately 230 differentiated tumors (18). Using multivariable analysis, severe obesity emerged as an 231 independent risk factor of decreased RFS. The difference in RFS was not related to 232 epidemiological characteristics as no difference in co-morbidities such as hypertension and 233 diabetes was noted between patients with a $\mathrm{BMI}<35$ and those with a higher BMI. 234 Differences in survival in obese patients can be explained by various histological parameters. 235 There is a trend for a higher incidence of LVSI in severely obese patients. Indeed, a recent 236 study demonstrated that the recurrence rate for the high-risk group was $25.9 \%$ in case of 237 negative LVSI and $45.1 \%$ for those with positive LVSI (30). In addition, in a study collecting 238 data of 10 cohorts and 14 case-control studies from the Epidemiology of Endometrial Cancer 239 Consortium with a total of 14,069 EC cases and 35,312 controls, Setiawan et al. concluded 240 that risk factors for high-grade endometrioid and type II cancer were similar (31). Considering 241 specifically type II or high grade endometrial cancers groups, Ko et al. (32) found that BMI 242 was not associated with decreased RFS or OS, which is in contradiction with our results. 243 However, in the latter study, little evidence was provided about the surgical management of 244 patients according to BMI.

245 In the current study, decreased RFS was not explained by under-treatment of women with 246 severe obesity. According to the current ESMO guidelines, women with high-risk EC should 247 be treated by total hysterectomy with bilateral salpingo-oophorectomy, systematic pelvic and 248 para-aortic lymphadenectomy, pelvic radiotherapy and adjuvant chemotherapy according to 249 nodal status (5). Previous studies documented that increasing obesity significantly impacts the 250 decision to perform lymphadenectomy in patients undergoing laparoscopic surgery, 
251 particularly because of a higher postoperative complication rate (i.e. wound infection and

252 venous thrombophlebitis) (28). However, in the present study, no difference in surgical

253 management was noted especially concerning the rate of pelvic and para-aortic

254 lymphadenectomy. According to the literature, difficulties are also encountered to complete

255 protocols of adjuvant radiotherapy (6) and chemotherapy (7) in obese women. Yet no

256 difference in adjuvant therapies was observed in our population of severely obese women in

257 the high-risk group. Finally, biological changes associated with obesity could be another 258 explanation of a lower RFS. Indeed, obesity is associated with low-grade chronic 259 inflammation (33), chronic hyperinsulinaemia, alterations in the production of peptide and 260 steroid hormones which are postulated mechanisms involved in cancer development (34).

261 Previous studies have shown that the adipose tissue of obese women leads to the synthesis of

262 high levels of estradiol and that frequent anovulation among obese premenopausal women 263 leads to progesterone deficiency and unopposed estrogen exposure (26, 35). Thus, as 264 emphasized by Akhmedkhanov et al., these biological changes are responsible for 265 endometrial cell proliferation, inhibition of apoptosis, and an increased number of DNA 266 replication errors and somatic mutations (36). These biological disturbances and an 267 inflammatory environment promoted by obesity may lead to cancer development or 268 recurrence (37).

270 Some limitations of the present study deserve to be underlined. First, we cannot exclude bias

271 linked to the retrospective nature of the study. Second, the long period study from 2000 to 272 2012, meant that the patients included underwent different surgical management (i.e. 273 systematic pelvic lymphadenectomy before 2010 which was only recommended for high risk 274 ECs from 2010 according to the revised French guidelines) (24). Another factor was the 275 introduction of the SLN biopsy in 2004 resulting in the detection of occult lymph node 
metastasis. Indeed, Raimond et al. demonstrated the impact of SLN biopsy on indications of

277 adjuvant therapies impacting recurrence rate (38). Third, we did not take into account 278 physical activity and diet although several authors have previously shown that these factors 279 may normalize hormone receptor expression profiles in the endometrium and positively 280 influence survival (39). However, a recent study concerning 983 postmenopausal women with 281 EC, found that physical activity was not associated with survival (18). Finally, we did not 282 include for analysis the type of diabetes treatment. Zhang et al. recently showed that 283 metformin could positively impact progression of EC probably via induction of CGRRF1 284 (cell growth regulator with ring finger domain) gene expression (40).

\section{Conclusion}

287 Our results support that severe obesity negatively impacts RFS in women with high-risk EC, underlining the importance of complete surgical staging and adapted adjuvant therapies in this subgroup of women. This is of major importance as physicians might be tempted to undertreat severely obese women with EC to avoid complications related to lymphadenectomy and/or adjuvant therapies. Future studies should focus on this subgroup of obese women with high-risk EC and possibly include the evaluation of physical activity, diet and comorbidities. 


\section{References}

304 1. Reeves KW, Carter GC, Rodabough RJ, Lane D, McNeeley SG, Stefanick ML, 305 Paskett ED. Obesity in relation to endometrial cancer risk and disease characteristics in the 306 Women's Health Initiative. Gynecol Oncol. 2011 May 1;121(2):376-82.

307 2. Jeong NH, Lee JM, Lee JK, Kim JW, Cho CH, Kim SM, Seo SS, et al. Role of body 308 mass index as a risk and prognostic factor of endometrioid uterine cancer in Korean women. 309 Gynecol Oncol. 2010 Jul;118(1):24-8.

$3103 . \quad$ Calle EE, Rodriguez C, Walker-Thurmond K, Thun MJ. Overweight, obesity, and 311 mortality from cancer in a prospectively studied cohort of U.S. adults. N Engl J Med. 2003 312 Apr 24;348(17):1625-38.

313 4. Nagle CM, Marquart L, Bain CJ, O'Brien S, Lahmann PH, Quinn M, Oehler MK, et

314 al. Impact of weight change and weight cycling on risk of different subtypes of endometrial 315 cancer. Eur J Cancer. 2013 Aug;49(12):2717-26.

316 5. Colombo N, Preti E, Landoni F, Carinelli S, Colombo A, Marini C, Sessa C. 317 Endometrial cancer: ESMO Clinical Practice Guidelines for diagnosis, treatment and follow318 up. Ann Oncol. 2013 Oct;24 Suppl 6:vi33-8.

319 6. Lin LL, Hertan L, Rengan R, Teo BK. Effect of body mass index on magnitude of 320 setup errors in patients treated with adjuvant radiotherapy for endometrial cancer with daily 321 image guidance. Int J Radiat Oncol Biol Phys. 2012 Jun 1;83(2):670-5.

322 7. Modesitt SC, Tian C, Kryscio R, Thigpen JT, Randall ME, Gallion HH, Fleming GF. 323 Impact of body mass index on treatment outcomes in endometrial cancer patients receiving 324 doxorubicin and cisplatin: a Gynecologic Oncology Group study. Gynecol Oncol. 2007 325 Apr;105(1):59-65. 
327 Obesity and prognosis in endometrial cancer. Am J Obstet Gynecol. 1996 Apr;174(4):1171-8;

328 discussion 8-9.

329 9. Everett E, Tamimi H, Greer B, Swisher E, Paley P, Mandel L, Goff B. The effect of 330 body mass index on clinical/pathologic features, surgical morbidity, and outcome in patients 331 with endometrial cancer. Gynecol Oncol. 2003 Jul;90(1):150-7.

332 10. Gates EJ, Hirschfield L, Matthews RP, Yap OW. Body mass index as a prognostic 333 factor in endometrioid adenocarcinoma of the endometrium. J Natl Med Assoc. 2006 334 Nov;98(11):1814-22.

335 11. Munstedt K, Wagner M, Kullmer U, Hackethal A, Franke FE. Influence of body mass 336 index on prognosis in gynecological malignancies. Cancer Causes Control. 2008 337 Nov;19(9):909-16.

338 12. Temkin SM, Pezzullo JC, Hellmann M, Lee YC, Abulafia O. Is body mass index an 339 independent risk factor of survival among patients with endometrial cancer? Am J Clin Oncol. 3402007 Feb;30(1):8-14.

341 13. Kodama J, Seki N, Ojima Y, Nakamura K, Hongo A, Hiramatsu Y. Risk factors for 342 early and late postoperative complications of patients with endometrial cancer. Eur J Obstet 343 Gynecol Reprod Biol. 2006 Feb 1;124(2):222-6.

344 14. Studzijnski Z, Zajewski W. Factors affecting the survival of 121 patients treated for 345 endometrial carcinoma at a Polish hospital. Arch Gynecol Obstet. 2003 Jan;267(3):145-7.

346 15. Chia VM, Newcomb PA, Trentham-Dietz A, Hampton JM. Obesity, diabetes, and 347 other factors in relation to survival after endometrial cancer diagnosis. Int J Gynecol Cancer. 3482007 Mar-Apr;17(2):441-6.

349 16. Mauland KK, Trovik J, Wik E, Raeder MB, Njolstad TS, Stefansson IM, Oyan AM, et 350 al. High BMI is significantly associated with positive progesterone receptor status and 
351 clinico-pathological markers for non-aggressive disease in endometrial cancer. $\mathrm{Br} \mathrm{J}$ Cancer. 3522011 Mar 15;104(6):921-6.

353 17. von Gruenigen VE, Tian C, Frasure H, Waggoner S, Keys H, Barakat RR. Treatment 354 effects, disease recurrence, and survival in obese women with early endometrial carcinoma : a 355 Gynecologic Oncology Group study. Cancer. 2006 Dec 15;107(12):2786-91.

356 18. Arem H, Chlebowski R, Stefanick ML, Anderson G, Wactawski-Wende J, Sims S, 357 Gunter MJ, et al. Body mass index, physical activity, and survival after endometrial cancer 358 diagnosis: results from the Women's Health Initiative. Gynecol Oncol. 2013 Feb;128(2):1813596.

360 19. Flegal KM, Graubard BI, Williamson DF, Gail MH. Cause-specific excess deaths 361 associated with underweight, overweight, and obesity. JAMA. 2007 Nov 7;298(17):2028-37.

362 20. Zanders MM, Boll D, van Steenbergen LN, van de Poll-Franse LV, Haak HR. Effect 363 of diabetes on endometrial cancer recurrence and survival. Maturitas. 2013 Jan;74(1):37-43.

364 21. Ballester M, Dubernard G, Lecuru F, Heitz D, Mathevet P, Marret H, Querleu D, et al. 365 Detection rate and diagnostic accuracy of sentinel-node biopsy in early stage endometrial 366 cancer: a prospective multicentre study (SENTI-ENDO). Lancet Oncol. 2011 May;12(5):469$367 \quad 76$.

368 22. Clinical Guidelines on the Identification, Evaluation, and Treatment of Overweight 369 and Obesity in Adults--The Evidence Report. National Institutes of Health. Obes Res. 1998 370 Sep;6 Suppl 2:51S-209S.

371 23. Petru E, Luck HJ, Stuart G, Gaffney D, Millan D, Vergote I. Gynecologic Cancer 372 Intergroup (GCIG) proposals for changes of the current FIGO staging system. Eur J Obstet 373 Gynecol Reprod Biol. 2009 Apr;143(2):69-74.

374 24. Cancer de l'endomètre, Collection Recommandations \& référentiels, INCa, Boulogne375 Billancourt, novembre 2010. 
25. Delpech Y, Cortez A, Coutant C, Callard P, Uzan S, Darai E, Barranger E. The

377 sentinel node concept in endometrial cancer: histopathologic validation by serial section and 378 immunohistochemistry. Ann Oncol. 2007 Nov;18(11):1799-803.

379 26. Arem H, Irwin ML. Obesity and endometrial cancer survival: a systematic review. Int 380 J Obes (Lond). 2013 May;37(5):634-9.

381 27. Crosbie EJ, Roberts C, Qian W, Swart AM, Kitchener HC, Renehan AG. Body mass 382 index does not influence post-treatment survival in early stage endometrial cancer: results 383 from the MRC ASTEC trial. Eur J Cancer. 2012 Apr;48(6):853-64.

384 28. Gunderson CC, Java J, Moore KN, Walker JL. The impact of obesity on surgical 385 staging, complications, and survival with uterine cancer: A Gynecologic Oncology Group 386 LAP2 ancillary data study. Gynecol Oncol. 2014 Apr;133(1):23-7.

387 29. May K, Bryant A, Dickinson HO, Kehoe S, Morrison J. Lymphadenectomy for the 388 management of endometrial cancer. Cochrane Database Syst Rev. 2010(1):CD007585.

389 30. Bendifallah S, Canlorbe G, Raimond E, Hudry D, Coutant C, Graesslin O, Touboul C, 390 et al. A clue towards improving the European Society of Medical Oncology risk group 391 classification in apparent early stage endometrial cancer? Impact of lymphovascular space 392 invasion. Br J Cancer. 2014 May 27;110(11):2640-6.

393 31. Setiawan VW, Yang HP, Pike MC, McCann SE, Yu H, Xiang YB, Wolk A, et al. 394 Type I and II endometrial cancers: have they different risk factors? J Clin Oncol. 2013 Jul 395 10;31(20):2607-18.

396 32. Ko EM, Walter P, Clark L, Jackson A, Franasiak J, Bolac C, Havrilesky L, et al. The 397 complex triad of obesity, diabetes and race in Type I and II endometrial cancers: Prevalence 398 and prognostic significance. Gynecol Oncol. 2014 Apr;133(1):28-32.

399 33. Catalan V, Gomez-Ambrosi J, Rodriguez A, Fruhbeck G. Adipose tissue immunity 400 and cancer. Front Physiol. 2013;4:275. 
401 34. Calle EE, Thun MJ. Obesity and cancer. Oncogene. 2004 Aug 23;23(38):6365-78.

402 35. Calle EE, Kaaks R. Overweight, obesity and cancer: epidemiological evidence and 403 proposed mechanisms. Nat Rev Cancer. 2004 Aug;4(8):579-91.

404 36. Akhmedkhanov A, Zeleniuch-Jacquotte A, Toniolo P. Role of exogenous and 405 endogenous hormones in endometrial cancer: review of the evidence and research 406 perspectives. Ann N Y Acad Sci. 2001 Sep;943:296-315.

407 37. Dossus L, Rinaldi S, Becker S, Lukanova A, Tjonneland A, Olsen A, et al. Obesity, 408 inflammatory markers, and endometrial cancer risk: a prospective case-control study. Endocr 409 Relat Cancer. 2010 Dec;17(4):1007-19.

410 38. Raimond E, Ballester M, Hudry D, Bendifallah S, Darai E, Graesslin O, Stegger J, et 411 al. Impact of sentinel lymph node biopsy on the therapeutic management of early-stage 412 endometrial cancer: Results of a retrospective multicenter study. Gynecol Oncol. 2014 Mar 41315.

414 39. Pekmezi DW, Demark-Wahnefried W. Updated evidence in support of diet and 415 exercise interventions in cancer survivors. Acta Oncol. 2011 Feb;50(2):167-78.

416 40. Zhang Q, Schmandt R, Celestino J, McCampbell A, Yates MS, Urbauer DL, Broaddus 417 RR, et al. CGRRF1 as a novel biomarker of tissue response to metformin in the context of 418 obesity. Gynecol Oncol. 2014 Apr;133(1):83-9. 
428 Table 1. Epidemiological, histological and therapeutic characteristics by BMI in the whole 429 population. IQR: interquartile range.

430

431 Table 2. Characteristics of obese women according to ESMO risk groups of recurrence. IQR:

432 interquartile range.

433

434 Figure 1. Recurrence-Free Survival according to BMI subgroup in the whole population.

435

436 Figure 2. Recurrence-Free Survival in obese women in high-risk group.

437

438

439 


\begin{tabular}{|c|c|c|c|c|c|}
\hline & & $\begin{array}{c}B M I<30 \\
n=442\end{array}$ & $\begin{array}{c}30 \leq B M \mid<35 \\
n=146\end{array}$ & $\begin{array}{l}B M I \geq 35 \\
n=141\end{array}$ & $\mathbf{p}$ \\
\hline Median ag & , years (IQR) & $65.5(59-74.5)$ & $66(60-71)$ & $63(56-70)$ & 0.000873 \\
\hline \multicolumn{6}{|c|}{ Histological type (\%) } \\
\hline & Type I & $371(84)$ & $126(86)$ & $135(96)$ & \multirow{2}{*}{$<0.005$} \\
\hline & Type II & $71(16)$ & $20(14)$ & $6(4)$ & \\
\hline \multicolumn{6}{|c|}{ Histological grade (\%) } \\
\hline & Grade 1 & $201(45)$ & $66(45)$ & $86(61)$ & \multirow{3}{*}{0.009} \\
\hline & Grade 2 & $122(28)$ & $38(26)$ & $34(24)$ & \\
\hline & Grade 3 & $119(27)$ & $42(29)$ & $21(15)$ & \\
\hline \multicolumn{6}{|c|}{ Depth of myometrial invasion (\%) } \\
\hline & $<50 \%$ & $239(54)$ & $74(51)$ & $86(61)$ & \multirow{2}{*}{0.2628} \\
\hline & $>50 \%$ & $195(44)$ & $68(47)$ & $54(38)$ & \\
\hline \multicolumn{6}{|c|}{ ESMO risk group(\%) } \\
\hline & Low risk & $198(45)$ & $58(40)$ & $79(56)$ & \multirow{3}{*}{0.01595} \\
\hline & Intermediate risk & $141(32)$ & $54(37)$ & $45(32)$ & \\
\hline & High risk & $103(23)$ & $34(23)$ & $17(12)$ & \\
\hline \multicolumn{6}{|c|}{ Lymphovascular space invasion (\%) } \\
\hline & Present & $119(27)$ & $40(27)$ & $32(23)$ & \multirow{2}{*}{0.442} \\
\hline & Not present & $284(64)$ & $91(62)$ & $100(71)$ & \\
\hline \multicolumn{6}{|c|}{ FIGO stage (\%) } \\
\hline & IA & $209(47)$ & $61(42)$ & $72(51)$ & \multirow{8}{*}{0.8437} \\
\hline & IB & $112(25)$ & $46(32)$ & $38(27)$ & \\
\hline & II & $32(7)$ & $9(6)$ & $9(6)$ & \\
\hline & IIIA & $16(4)$ & $6(4)$ & $7(5)$ & \\
\hline & IIIB & $4(1)$ & $3(2)$ & $2(1)$ & \\
\hline & IIIC & $58(13)$ & $16(11)$ & $12(9)$ & \\
\hline & IVA & $3(<1)$ & $1(1)$ & 0 & \\
\hline & IVB & $6(1)$ & $3(2)$ & $1(1)$ & \\
\hline \multicolumn{6}{|c|}{ Lymphadenectomy (\%) } \\
\hline & Yes & $399(90)$ & $133(91)$ & $102(72)$ & \multirow{2}{*}{$<0.0001$} \\
\hline & No & $43(10)$ & $13(9)$ & $39(28)$ & \\
\hline \multicolumn{6}{|c|}{ Nodal involvement (\%) } \\
\hline & Yes & $63(14)$ & $21(14)$ & $13(9)$ & \multirow{2}{*}{0.7363} \\
\hline & No & $336(76)$ & $112(77)$ & $89(63)$ & \\
\hline \multicolumn{6}{|c|}{ External beam radiotherapy (\%) } \\
\hline & Yes & $163(37)$ & $64(44)$ & $51(36)$ & \multirow{2}{*}{0.2245} \\
\hline & No & $259(59)$ & $73(50)$ & $81(57)$ & \\
\hline \multicolumn{6}{|c|}{ Brachytherapy (\%) } \\
\hline & Yes & $222(50)$ & $76(52)$ & $76(54)$ & \multirow{2}{*}{0.5451} \\
\hline & No & $187(42)$ & $56(38)$ & $52(37)$ & \\
\hline \multicolumn{6}{|c|}{ Chemotherapy (\%) } \\
\hline & Yes & $73(17)$ & $16(11)$ & $15(11)$ & \multirow{2}{*}{0.1197} \\
\hline & No & $350(79)$ & $120(82)$ & $118(84)$ & \\
\hline \multicolumn{6}{|c|}{ Recurrence } \\
\hline & Yes & $62(14)$ & $20(14)$ & $21(15)$ & \\
\hline & No & $380(86)$ & $126(86)$ & $120(85)$ & 0.9541 \\
\hline
\end{tabular}

Table 1. Epidemiological, histological and therapeutic characteristics by BMI in the whole population. IQR: interquartile range. 
Low-risk group, $n=137$

$30 \leq \mathrm{BMI}<35$

\begin{tabular}{c|c|c}
$\mathrm{n}=58$ & $\mathrm{n}=79$ & $\mathrm{p}$
\end{tabular}

\begin{tabular}{c|c|c}
\hline $64.5(60-71)$ & $60(56-68)$ & 0.1305
\end{tabular}

Median age, years (IQR

Histological type, $\mathrm{n}(\%)$

\begin{tabular}{|c|c|}
\hline & Type I \\
\hline & Type II \\
\hline Lymphovascular & space invasion, $n(\%)$ \\
\hline & Present \\
\hline & Not Present \\
\hline FIGO stage, $\mathrm{n}(\%$ & \\
\hline & $\mathrm{IA}$ \\
\hline & $\mathrm{IB}$ \\
\hline & II \\
\hline & IIIA \\
\hline & IIIB \\
\hline & IIIC \\
\hline & IVA \\
\hline & IVB \\
\hline Lymphadenecton & $y, n(\%)$ \\
\hline & Yes \\
\hline & No \\
\hline Number of nodes & removed, median (IQR) \\
\hline Nodal involveme & $\mathrm{t}, \mathrm{n}(\%)$ \\
\hline & Yes \\
\hline & No \\
\hline External Beam R & diotherapy, n(\%) \\
\hline & Yes \\
\hline & No \\
\hline Brachytherapy, n & \\
\hline & Yes \\
\hline & No \\
\hline Chemotherapy, $\mathrm{n}$ & \\
\hline & Yes \\
\hline & No \\
\hline Recurrence, $\mathrm{n}(\%$ & \\
\hline 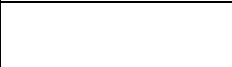 & Yes \\
\hline
\end{tabular}

\begin{tabular}{|c|c|c|}
\hline $58(100)$ & $79(100)$ & \\
\hline 0 & 0 & \\
\hline $6(10)$ & $2(3)$ & \multirow{2}{*}{0.062} \\
\hline $45(78)$ & 72 (91) & \\
\hline 49 (84) & $68(86)$ & \multirow{8}{*}{0.9849} \\
\hline $3(5)$ & $5(6)$ & \\
\hline $2(3)$ & $2(3)$ & \\
\hline $1(2)$ & $1(1)$ & \\
\hline 0 & 0 & \\
\hline $3(5)$ & $3(4)$ & \\
\hline 0 & 0 & \\
\hline 0 & 0 & \\
\hline 54 (93) & 56 (71) & \multirow{2}{*}{0.00107} \\
\hline $4(7)$ & $23(29)$ & \\
\hline $11(10-17)$ & $11.5(8-12)$ & 0.3504 \\
\hline $4(7)$ & $3(4)$ & \multirow{2}{*}{0.7137} \\
\hline $50(86)$ & $53(67)$ & \\
\hline $12(21)$ & 11 (14) & \multirow{2}{*}{0.4308} \\
\hline $43(74)$ & $63(80)$ & \\
\hline $25(43)$ & $36(46)$ & \multirow{2}{*}{0.8557} \\
\hline $27(47)$ & 35 (44) & \\
\hline $3(5)$ & $1(1)$ & \multirow{2}{*}{0.3096} \\
\hline $51(88)$ & 73 (92) & \\
\hline $2(3)$ & $3(4)$ & \multirow[b]{2}{*}{1} \\
\hline 56 (97) & $76(96)$ & \\
\hline
\end{tabular}

Intermediate-risk group, $\mathrm{n}=99$

High-risk group, $n=51$

\begin{tabular}{|c|c|c|c|c|c|}
\hline $\begin{array}{c}30 \leq \mathrm{BMI}<35 \\
\mathrm{n}=54\end{array}$ & $\begin{array}{c}\mathrm{BMI} \geq 35 \\
\mathrm{n}=45\end{array}$ & $p$ & $\begin{array}{c}30 \leq \mathrm{BM} \mid<35 \\
\mathrm{n}=34\end{array}$ & $\begin{array}{c}\mathrm{BMI} \geq 35 \\
\mathrm{n}=17\end{array}$ & $p$ \\
\hline 66 (62-71) & $64(54-70.2)$ & 0.1285 & $66(60-73)$ & 69 (64-71) & 0.4074 \\
\hline $54(100)$ & $45(100)$ & \multirow[b]{2}{*}{ - } & $14(41)$ & $11(65)$ & \multirow{2}{*}{0.1441} \\
\hline 0 & 0 & & $20(59)$ & $6(35)$ & \\
\hline & & & & & \\
\hline $15(28)$ & $19(42)$ & \multirow{2}{*}{0.3192} & $19(56)$ & $11(65)$ & \multirow{2}{*}{0.5382} \\
\hline 31 (57) & $23(51)$ & & $15(44)$ & $5(29)$ & \\
\hline $4(7)$ & $2(4)$ & \multirow{8}{*}{0.2032} & $8(24)$ & $2(12)$ & \multirow{8}{*}{0.3215} \\
\hline $37(69)$ & $25(56)$ & & $6(18)$ & $8(47)$ & \\
\hline $5(9)$ & 6 (13) & & $2(6)$ & $1(6)$ & \\
\hline $1(2)$ & $6(13)$ & & $4(12)$ & 0 & \\
\hline $1(2)$ & 0 & & $2(6)$ & 2 (12) & \\
\hline $5(9)$ & $6(13)$ & & $8(24)$ & $3(18)$ & \\
\hline $1(2)$ & 0 & & 0 & 0 & \\
\hline 0 & 0 & & $3(9)$ & $1(6)$ & \\
\hline $48(89)$ & $32(71)$ & \multirow{2}{*}{0.030} & 31 (91) & $14(82)$ & \multirow{2}{*}{0.3871} \\
\hline $6(11)$ & $13(29)$ & & $3(9)$ & $3(18)$ & \\
\hline $13(9-15.7)$ & $13(10.5-17.5)$ & 0.7474 & 17 (11.5-23) & $12(7.5-19.2)$ & 0.1151 \\
\hline & & \multirow{3}{*}{0.3558} & & & \multirow{3}{*}{0.4921} \\
\hline $6(11)$ & $7(16)$ & & $11(32)$ & $3(18)$ & \\
\hline $42(78)$ & $25(56)$ & & $20(59)$ & $11(65)$ & \\
\hline $29(54)$ & $27(60)$ & \multirow{2}{*}{0.6885} & $23(68)$ & $13(76)$ & \multirow{2}{*}{0.7252} \\
\hline $21(39)$ & $15(33)$ & & $9(26)$ & $3(18)$ & \\
\hline & & \multirow{3}{*}{0.8956} & & & \multirow{3}{*}{1} \\
\hline $37(69)$ & $33(73)$ & & $14(41)$ & $7(41)$ & \\
\hline $11(20)$ & $8(18)$ & & $18(53)$ & $9(53)$ & \\
\hline $3(6)$ & $7(16)$ & \multirow[b]{2}{*}{0.1785} & $10(29)$ & $7(41)$ & \\
\hline 47 (87) & $36(80)$ & & $22(65)$ & $9(53)$ & 0.5242 \\
\hline & & & & & \\
\hline $5(9)$ & $9(20)$ & \multirow{2}{*}{0.1542} & $13(38)$ & $9(53)$ & \multirow[b]{2}{*}{0.4841} \\
\hline 49 (91) & $36(80)$ & & $21(62)$ & $8(47)$ & \\
\hline
\end{tabular}

Table 2. Characteristics of obese women according to ESMO risk groups of recurrence. IQR: interquartile range. 


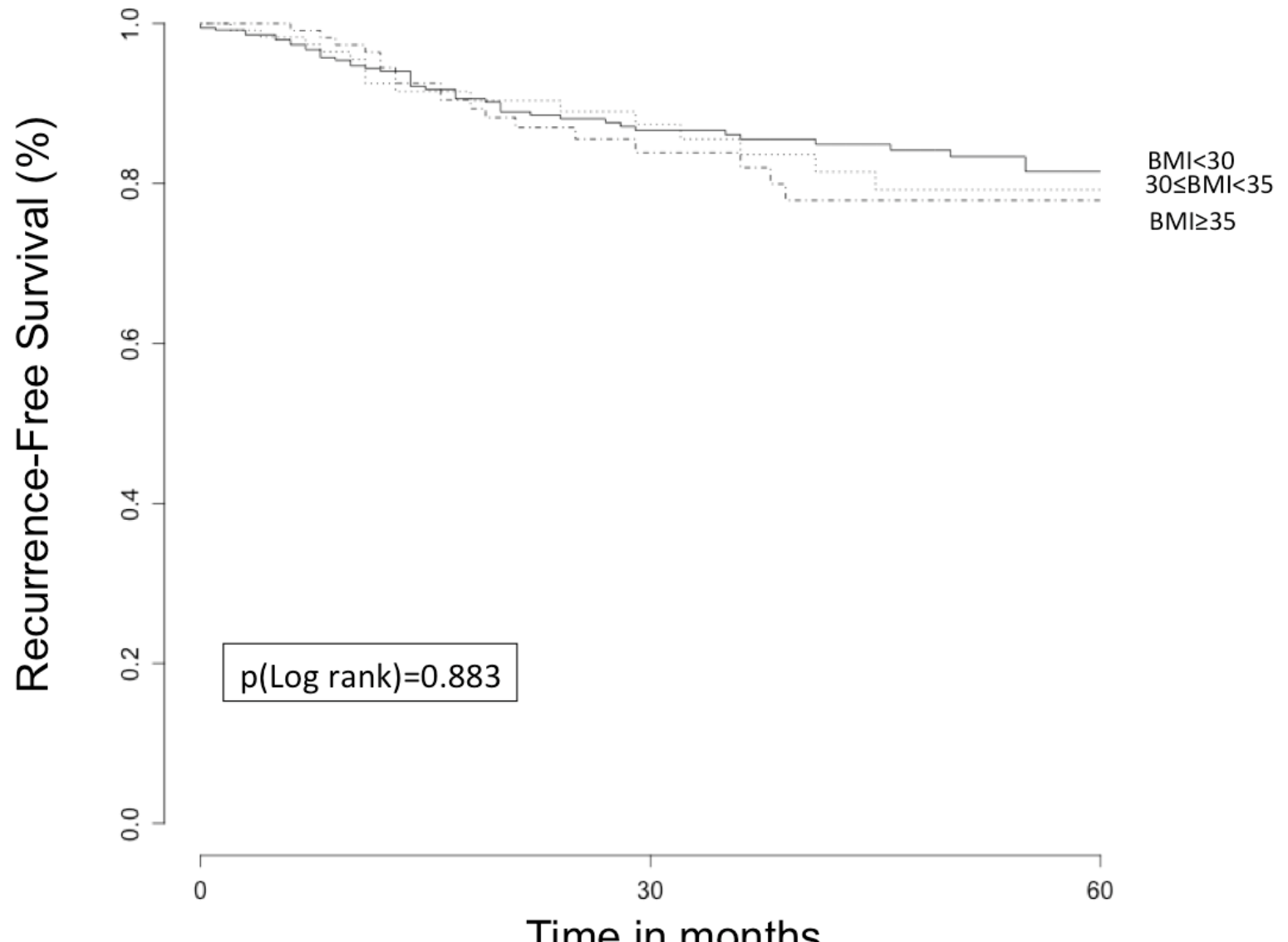

Time in months

441 Figure 1. Recurrence-Free Survival according to BMI subgroup in the whole population. 


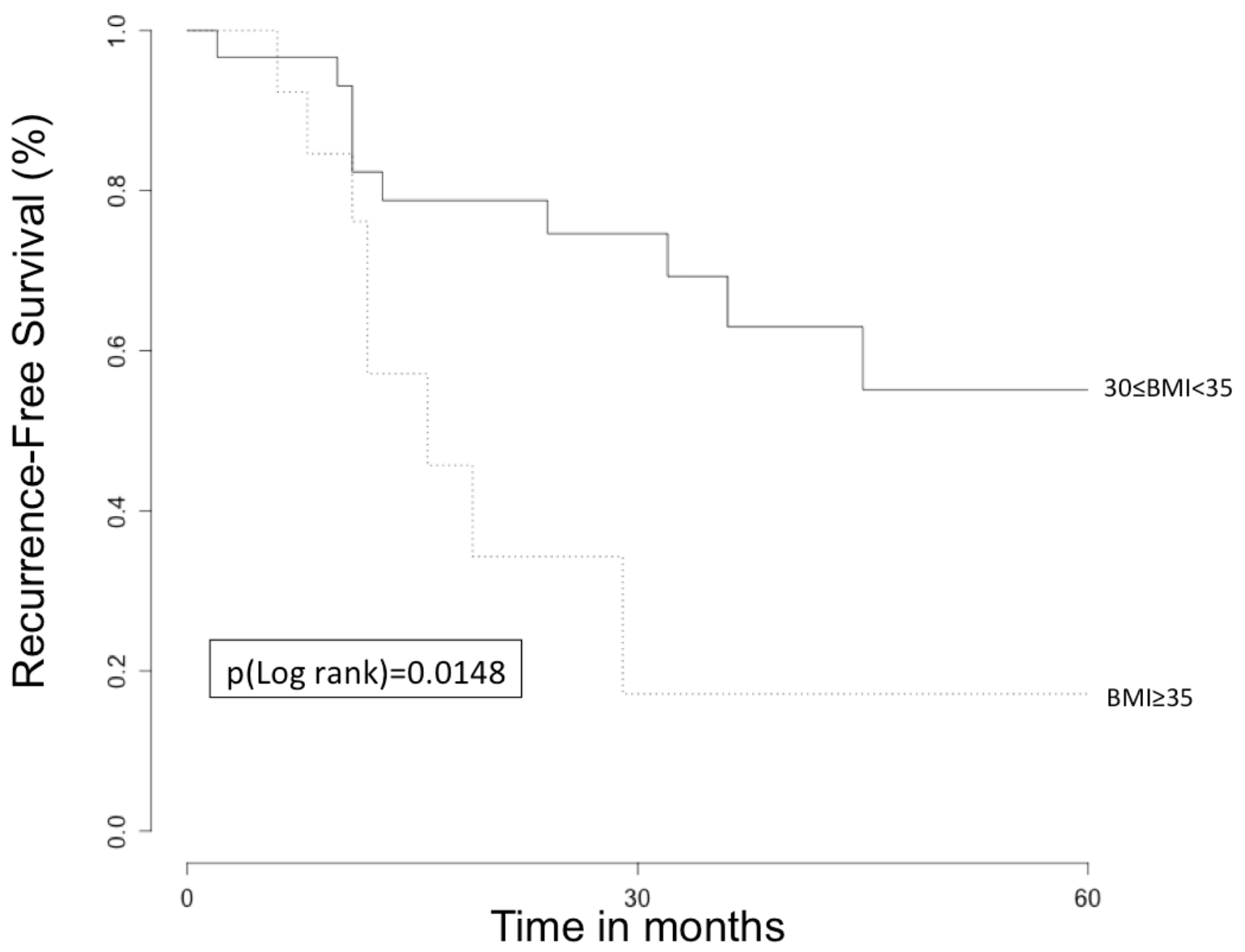

443

444 Figure 2. Recurrence-Free Survival in obese women in high-risk group.

445 